\title{
Morpho-functional evaluation of lung aeration as a marker of sickle-cell acute chest syndrome severity in the ICU: a prospective cohort study
}

\author{
Marc Garnier ${ }^{1,2,3^{*}}$ (D) El Mahdi Hafiani ${ }^{1,2}$, Charlotte Arbelot ${ }^{4}$, Clarisse Blayau $^{1,2}$, Vincent Labbe ${ }^{2}$, \\ Katia Stankovic-Stojanovic ${ }^{5}$, François Lionnet ${ }^{5}$, Francis Bonnet ${ }^{1,3}$, Jean-Pierre Fulgencio ${ }^{1,2}$, Muriel Fartoukh ${ }^{2,3}$ \\ and Christophe Quesnel ${ }^{1,3}$
}

\begin{abstract}
Background: Acute chest syndrome (ACS) is the main cause of morbi-mortality in patients with sickle-cell disease in the intensive care unit (ICU). ACS definition encompasses many types of lung damage, making early detection of the most severe forms challenging. We aimed to describe ACS-related lung ultrasound (LU) patterns and determine LU performance to assess ACS outcome.

Results: We performed a prospective cohort study including $56 \mathrm{ICU}$ patients hospitalized for ACS in a tertiary university hospital (Paris, France). LU and bedside spirometry were performed at admission (D0) and after $48 \mathrm{~h}$ (D2). Complicated outcome was defined by the need for transfusion of $\geq 3$ red blood cell units, mechanical ventilation, ICU length-of-stay $>5$ days, or death. A severe loss of lung aeration was observed in all patients, predominantly in inferior lobes, and was associated with decreased vital capacity (22 [15-33]\% of predicted). The LU Score was 24 [20-28] on D0 and 20 [15-24] on D2. Twenty-five percent of patients (14/56) had a complicated outcome. Neither oxygen supply, pain score, haemoglobin, LDH and bilirubin values at D0; nor their change at D2, differed regarding patient outcome. Conversely, LU re-aeration score and spirometry change at D2 improved significantly more in patients with a favourable outcome. A negative LU re-aeration score at D2 was an independent marker of severity of ACS in ICU.
\end{abstract}

Conclusions: ACS is associated with severe loss of lung aeration, whose resolution is associated with favourable outcome. Serial bedside LU may accurately and early identify ACS patients at risk of complicated outcome.

Keywords: Acute chest syndrome, Sickle-cell disease, Acute lung injury, Lung ultrasound, Bedside spirometry

\section{Background}

Sickle-cell disease (SCD) is one of the most frequent haemoglobinopathies worldwide. Its overall prevalence is not well determined in developed countries, but its incidence is still increasing, reaching over 4500 newborns in France over the past 10 years [1]. Progress made in its management led to increased life expectancy in developed

\footnotetext{
*Correspondence: marcgarnier@gmail.com

1 Département d'Anesthésie et Réanimation, APHP Hôpital Tenon, 4 rue de la Chine, 75020 Paris, France

Full list of author information is available at the end of the article
}

countries [2], however patients with SCD are still at risk of early mortality due to acute chest syndrome (ACS) [1]. Half of adult deaths arise in the intensive care unit (ICU), where ACS represents the main source of mortality [24]. ACS is also the most frequent vaso-occlusive event leading to ICU admission, and can lead to substantial morbidity [3]. Its typical presentation is a sudden onset of cough, dyspnoea, fever and rales, accompanied by new pulmonary infiltrate on chest radiography [5]. However, lung damage may vary from interstitial infiltrates to alveolar condensation, including atelectasis, pleural effusion, and in the worst case acute respiratory distress syndrome 
$[6,7]$. Thus, a simple tool allowing estimating the initial extent of ACS-related lung injury and its early evolution is required to avoid delayed management and improve severe ACS patient care.

Bedside assessment of lung injury in severe ACS patients, and consequently of lung aeration, is challenging. Chest X-ray is now considered a very imperfect tool in ICU patients, showing low sensitivity and specificity particularly for the diagnosis of alveolar consolidation $[8,9]$. CT-scan reported frequent large postero-lateral lung consolidations in severe ACS patients [9], but this exam cannot be used for daily bedside monitoring of ACS evolution. More recently, lung ultrasound (LU) has been reported as a reliable tool for diagnosis of lung condensation compared to CT-scan $[8,10]$. Finally, a functional approach could be used to estimate the amount of aerated lung, notably by measuring the Inspiratory Vital Capacity (IVC) at bedside when patients performed incentive spirometry $[11,12]$.

Hence, we aimed to assess the reliability of a bedside morpho-functional evaluation of ACS-related lung aeration loss for early detection of SCD patients who experience a complicated course during their ICU stay.

\section{Methods}

See Additional methods in Additional file 1.

This article follows the STROBE statement [13]. STROBE Checklist is available as an Additional file 2.

\section{Study population}

All patients over 18 years suffering from severe ACS were prospectively included in this single-centre prospective observational study within the first $12 \mathrm{~h}$ of admission into the Tenon University Hospital ICU (Paris, France) between March 2013 and September 2014. ACS was defined as new pulmonary infiltrate on the chest X-ray and at least one of the following criteria: fever, cough, acute dyspnoea, thoracic pain, pulmonary crackles or tubal blowing sound $[7,11]$. ACS severity was defined according to French recommendations (see Additional file 1: Methods) [11]. Patients re-admitted for a second severe ACS during the study period were not re-included. Patients with mixed thoracic disease, notably association of ACS with cardiogenic pulmonary oedema, were not included.

\section{Patient management}

Inclusion did not modify patient care, conducted according to French recommendations [11]. Briefly, standard care included bed rest, oxygen therapy, respiratory physiotherapy, incentive spirometry, intravenous hydration, and folate supplementation. Pain was managed using an incremental protocol adapted from national recommendations [11] (Additional file 3: Figure S1). Indication of red blood cell transfusion followed recommendations [11] and was systematically validated jointly by a local SCD referent physician and the attending intensivist before transfusion. An empirical antimicrobial therapy combining cefotaxime and spiramycin was initiated when the patient had fever, and secondarily adapted according to the final microbiological results [11].

\section{Data collection and outcome definition}

Clinical data were prospectively collected. Blood sampling for biological examinations was left to the discretion of the attending physicians. When available, biological data regarding blood gases, blood count, haemoglobin S dosage, liver function tests, and LDH concentrations were collected.

Complicated outcome was defined a priori according to previously published criteria, by occurrence of at least one of the following events: $\geq 3$ red blood cell (RBC) units transfused during ICU stay [3, 9, 14]; invasive or non-invasive mechanical ventilation requirement $[3,5$, 9]; ICU length-of-stay $>5$ days [3, 14, 15]; or in-hospital death.

\section{Lung ultrasound}

A first lung ultrasound (LU) examination was performed within the first $12 \mathrm{~h}$ of hospitalization in the ICU and recorded as video loops. Results were not provided to the attending physicians, ensuring that $\mathrm{LU}$ results did not affect patient management. A second LU examination was performed $48 \mathrm{~h}$ later for patients still hospitalized in the ICU by the same expert examiner $(E M-H)$ who performed all the examinations of this study. LU was performed using a $4-6 \mathrm{MHz}$ abdominal probe (Acuson ${ }^{\circledR}$ CV70, Siemens, Germany), investigating the 12 lung regions as previously described $[16,17]$. Then, two experts $(M G$ and $C A)$ independently examined the recorded LU video loops in random order. Each lung region was characterized by the worst ultrasound pattern observed, according to the four patterns previously described [16, 17] (normal aeration [N]; moderate loss of aeration [B1]; severe loss of aeration [B2]; and lung consolidation $[C]$, see characteristic LU patterns in Additional file 4: Video). Then, LU Score (LUS) at D0 and D2, and LU Re-aeration Score between D0 and D2 were calculated as previously described $[16,17]$.

\section{Lung inspiratory vital capacity measurement}

Lung inspiratory vital capacity (IVC) was measured during absence of pain (i.e., numeric pain scale $\leq 4$ ) by the attending physiotherapist after 5 cycles of normal ventilation followed by a forced expiration, using a volumetric exerciser (Voldyne ${ }^{\circledR}$ 2500, Teleflex ${ }^{\circledR}$ Medical) 
within the first $12 \mathrm{~h}$ of hospitalization in the ICU and in a period of $4 \mathrm{~h}$ before or after $\mathrm{LU}$ examination. IVC was recorded as the mean value of 3 consecutive measurements, according to international guidelines [18].

\section{Statistical analysis}

Data were expressed as median [25th-75th percentile]. Variables were analysed using non-parametric tests. Kaplan-Meier curves were plotted and a log rank test was performed to compare ICU and hospital lengthof-stays. A multivariate analysis of the predictors of complicated outcome was performed using a logistic regression model. Multivariate analysis was performed using a model including parameters with $p$ value $\leq 0.20$ in univariate analysis. A final model adjusted for age, baseline $\mathrm{Hb}$ and $\mathrm{LDH}$ value at inclusion was used to test the independent value of dynamic parameters to assess patient outcome.

$p<0.05$ was considered significant. Statistical analysis was performed with GraphPad Prism 6 (GraphPad Software, USA) and Statview 5.0 (SAS Institute Inc, USA).

\section{Results}

Patient characteristics

During the study period, 63 patients with severe ACS were referred to our unit, totalling 71 admissions. Among the 63 first episodes of ACS screened for eligibility, 56 were finally included (Fig. 1). Fourteen of the 56 patients (25\%) had a complicated outcome, among whom $14(100 \%)$ had an ICU length-of-stay $>5$ days, 7 (50\%) received $\geq 3 \mathrm{RBC}$ units during their ICU stay, and $2(14 \%)$ were mechanically ventilated. Baseline characteristics of patients with favourable and complicated outcomes were similar, except for a more frequent history of cholecystectomy in complicated patients (Table 1). Baseline severity of SCD, assessed by the severity score of Hebbel [19], modified by Lee et al. [20], was similar between the two groups (Table 1). Clinical and biological characteristics at inclusion were also similar between the two groups (Table 2).

\section{Clinico-biological data}

Daily mean $\mathrm{O}_{2}$ flow during the $24 \mathrm{~h}$ after inclusion was 3.3 [2.3-4.7] L/min. Oxygen delivery decreased from D0 to D2 (Table 3). There was no difference between patients with and without complicated outcome.

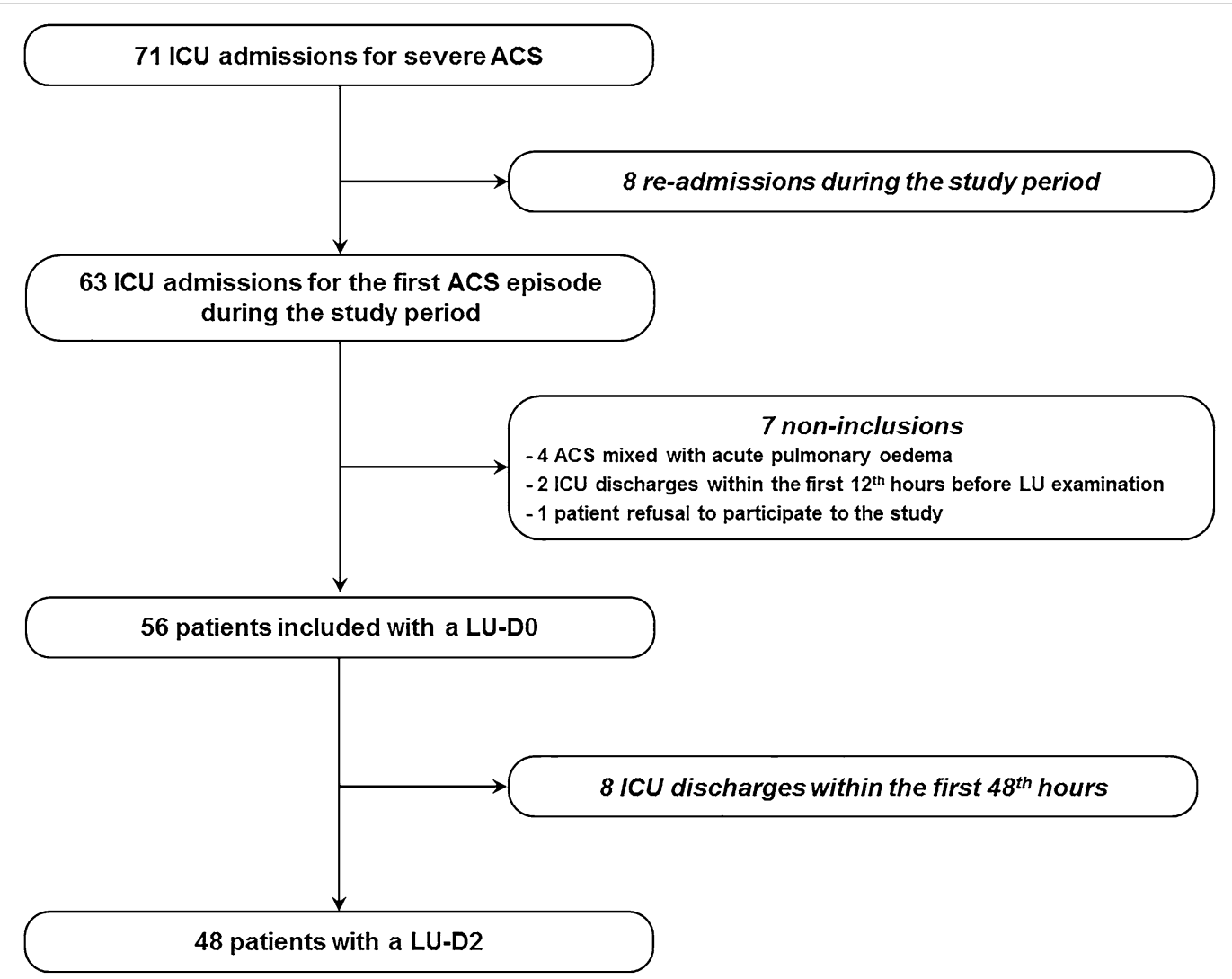

Fig. 1 Flow diagram of the study 
Table 1 Baseline characteristics of patients

\begin{tabular}{|c|c|c|c|c|}
\hline \multirow[t]{2}{*}{ Patients characteristics } & \multirow{2}{*}{$\begin{array}{l}\text { All patients } \\
(n=56)\end{array}$} & \multicolumn{2}{|l|}{ Patients with } & \multirow[t]{2}{*}{$p$} \\
\hline & & $\begin{array}{l}\text { Favourable outcome } \\
(n=42)\end{array}$ & $\begin{array}{l}\text { Complicated outcome } \\
(n=14)\end{array}$ & \\
\hline \multicolumn{5}{|l|}{ Demographic data, median [IQR] } \\
\hline Sex ratio (M/F) & $22 / 34$ & $17 / 25$ & $5 / 9$ & 0.75 \\
\hline Age (years) & $26.4[21.7-29.8]$ & $27.4[22.3-31.5]$ & $22.1[20.7-26.8]$ & 0.06 \\
\hline $\mathrm{BMI}\left(\mathrm{kg} / \mathrm{m}^{2}\right)$ & $21.3[19.8-23.6]$ & $21.7[19.8-23.4]$ & $20.8[20.2-24.7]$ & 0.78 \\
\hline \multicolumn{5}{|l|}{ Cause of hospital admission, \% (n) } \\
\hline Vaso-occlusive crisis & $48 \%(27)$ & $52 \%(32)$ & $43 \%(6)$ & 0.34 \\
\hline Acute chest syndrome & $46 \%(26)$ & $45 \%(19)$ & $50 \%(7)$ & \\
\hline Others & $6 \%(3)$ & $2 \%(1)$ & $7 \%(1)$ & \\
\hline \multicolumn{5}{|l|}{ Type of hemoglobinopathy, \% (n) } \\
\hline SS & $93 \%(52)$ & $90 \%(38)$ & $100 \%(14)$ & 0.23 \\
\hline $\mathrm{SC}$ & $7 \%(4)$ & $10 \%(4)$ & - & \\
\hline Baseline $\mathrm{Hb}(\mathrm{g} / \mathrm{dL})$, median [IQR] & $8.5[7.5-9.5]$ & $8.7[7.8-9.5]$ & 7.5 [7-9] & 0.08 \\
\hline \multicolumn{5}{|l|}{ Number of vaso-occlusive crises/year, \% (n) } \\
\hline 0 & $7 \%(4)$ & $5 \%(2)$ & $14 \%(2)$ & 0.47 \\
\hline $1-3$ & $70 \%(39)$ & $74 \%(31)$ & $57 \%(8)$ & \\
\hline $4-6$ & $21 \%(12)$ & $19 \%(8)$ & $29 \%(4)$ & \\
\hline$>6$ & $2 \%(1)$ & $2 \%(1)$ & $0 \%(0)$ & \\
\hline \multicolumn{5}{|l|}{ Sickle cell disease-related complication, \% (n) } \\
\hline Previous acute chest syndrome & $73 \%(41)$ & $74 \%(31)$ & $71 \%(10)$ & 0.86 \\
\hline $1-2$ & $34 \%(19)$ & $31 \%(13)$ & $43 \%(6)$ & 0.55 \\
\hline $3-4$ & $25 \%(14)$ & $26 \%(11)$ & $21 \%(3)$ & \\
\hline$>4$ & $14 \%(8)$ & $17 \%(7)$ & $7 \%(1)$ & \\
\hline Cholecystectomy & $35 \%(19)$ & $26 \%(11)$ & $57 \%(8)$ & 0.03 \\
\hline Non-septic osteonecrosis & $24 \%(14)$ & $24 \%(10)$ & $29 \%(4)$ & 0.72 \\
\hline Renal injury & $22 \%(12)$ & $26 \%(11)$ & $7 \%(1)$ & 0.13 \\
\hline Retinopathy & $20 \%(12)$ & $21 \%(9)$ & $21 \%(3)$ & 1.00 \\
\hline Priapism & $7 \%(4)$ & $10 \%(4)$ & $0 \%(0)$ & 0.23 \\
\hline Others & $15 \%(8)$ & $14 \%(6)$ & $14 \%(2)$ & 1.00 \\
\hline Clinical severity score of Hebbel, median [IQR] & $6[3-9]$ & $6[3-9]$ & $5.5[3-8]$ & 0.97 \\
\hline
\end{tabular}

Mean numeric pain scale during the $24 \mathrm{~h}$ following the inclusion was 4 [2.4-6] (Table 3). Pain and corresponding morphine use significantly decreased from D0 to D2 (Additional file 3: Figure S2). There were no between-group differences. All patients were treated by at least 2 classes of analgesics, of whom $98 \%$ received acetaminophen, 93\% morphine, 91\% nefopam, 48\% tramadol and 25\% ketamine.

Haemoglobin values at D0 did not differ between patients with favourable and complicated outcomes. Haemoglobin values increased significantly more at D2 in patients with a complicated outcome but these patients were more transfused (Table 3 ). Neither platelets count, $\mathrm{LDH}$ and bilirubin values at D0, nor their change at D2, differed between patients with favourable and complicated outcomes (Table 3 ).

\section{Lung ultrasound}

See details on LU patterns in Additional file 5: LU results.

At inclusion, a loss of aeration was found in all lung regions for the majority of patients, except for anterosuperior regions, without any difference according to patient outcome (Fig. 2). Forty-three patients (80\%) had bilateral postero-inferior lung consolidations. The LUS was 24 [20-28], without any difference according to patient outcome (Additional file 3: Figure S3A and Table 3). 
Table 2 Patient characteristics at inclusion

\begin{tabular}{|c|c|c|c|c|}
\hline \multirow[t]{2}{*}{ Patient characteristics } & \multirow{2}{*}{$\begin{array}{l}\text { All patients } \\
(n=56)\end{array}$} & \multicolumn{2}{|l|}{ Patients with } & \multirow[t]{2}{*}{$p$} \\
\hline & & $\begin{array}{l}\text { Favourable outcome } \\
(n=42)\end{array}$ & $\begin{array}{l}\text { Complicated outcome } \\
(n=14)\end{array}$ & \\
\hline \multicolumn{5}{|c|}{ Acute chest syndrome symptoms, \% (n) } \\
\hline Cough & $70 \%(39)$ & $69 \%(29)$ & $71 \%(10)$ & 0.17 \\
\hline Expectoration & $50 \%(28)$ & $52 \%(22)$ & $43 \%(6)$ & 0.54 \\
\hline Acute dyspnea & $82 \%(46)$ & $86 \%(36)$ & $71 \%(10)$ & 0.23 \\
\hline Mild & $35 \%(16 / 46)$ & $33 \%(12 / 36)$ & $40 \%(4 / 10)$ & 0.24 \\
\hline Moderate & $41 \%(19 / 46)$ & $47 \%(17 / 36)$ & $20 \%(2 / 10)$ & \\
\hline Severe & $24 \%(11 / 46)$ & $19 \%(7 / 36)$ & $40 \%(4 / 10)$ & \\
\hline Fever & $84 \%(47)$ & $83 \%(35)$ & $86 \%(12)$ & 0.83 \\
\hline Pulmonary rales & $95 \%(53)$ & $95 \%(40)$ & $93 \%(13)$ & 0.73 \\
\hline Crackling sounds & $75 \%(40 / 53)$ & $78 \%(31 / 40)$ & $69 \%(9 / 13)$ & \\
\hline Acute chest pain & $93 \%(52)$ & $93 \%(39)$ & $93 \%(13)$ & 1.00 \\
\hline Numeric pain scale value & $7[6-9]$ & $8[6-9]$ & $7[5.3-8.5]$ & 0.39 \\
\hline Other pain & $68 \%(38)$ & $67 \%(28)$ & $71 \%(10)$ & 0.74 \\
\hline Arms and/or legs & $48 \%(27)$ & $45 \%(19)$ & $57 \%(8)$ & 0.36 \\
\hline Back & $23 \%(13)$ & $24 \%(10)$ & $21 \%(3)$ & \\
\hline Abdomen & $9 \%(5)$ & $7 \%(3)$ & $14 \%(2)$ & \\
\hline Head and neck & $5 \%(3)$ & $5 \%(2)$ & $7 \%(1)$ & \\
\hline \multicolumn{5}{|l|}{ Clinical characteristics, median [IQR] } \\
\hline Heart rate (/min) & $100[87-111]$ & $99[86-111]$ & $102[88-113]$ & 0.73 \\
\hline Systolic blood pressure (mmHg) & 130 [115-139] & 130 [112-140] & 125 [122-138] & 0.93 \\
\hline Diastolic blood pressure $(\mathrm{mmHg})$ & $65[59-75]$ & $68[59-75]$ & $63[61-69]$ & 0.79 \\
\hline Respiratory rate (/min) & $24[20-29]$ & 23 [20-29] & $27[23-31]$ & 0.16 \\
\hline Inspiratory vital capacity (mL) & $1000[600-1250]$ & $1000[600-1300]$ & $750[500-1100]$ & 0.12 \\
\hline SOFA score (points) & $4[3-4]$ & $3[3-4]$ & $4[3-4]$ & 0.30 \\
\hline SAPS II (points) & $15[10.5-17]$ & $14[10-17]$ & 16 [13-18] & 0.32 \\
\hline \multicolumn{5}{|l|}{ Laboratory values, median [IQR] ${ }^{\mathrm{a}}$} \\
\hline Haemoglobin (g/dL) & $7.5[6.9-8.5]$ & $7.5[6.9-8.7]$ & $7.4[6.5-7.8]$ & 0.18 \\
\hline Haemoglobin S (\%) & $81[61-88]$ & $80[57-87]$ & $83[76-88]$ & 0.21 \\
\hline Platelets (G/L) & 327 [298-403] & 329 [264-403] & 325 [294-434] & 0.76 \\
\hline Lactate dehydrogenase (UI/L) & $544[420-745]$ & $503[403-715]$ & $613[525-834]$ & 0.09 \\
\hline Total bilirubin $(\mu \mathrm{mol} / \mathrm{L})$ & $47[33-79]$ & $55[38-79]$ & $36[29-44]$ & 0.06 \\
\hline Aspartate aminotranferase (UI/L) & $58[36-73]$ & $53[38-69]$ & $69[35-77]$ & 0.56 \\
\hline Alanine aminotransferase (UI/L) & 33 [18-52] & 32 [18- 49] & $35[18-51]$ & 0.87 \\
\hline \multicolumn{5}{|l|}{ Blood gas results, median [IQR] } \\
\hline $\mathrm{pH}$ & $7.39[7.36-7.41]$ & $7.39[7.36-7.41]$ & $7.38[7.35-7.42]$ & 0.71 \\
\hline $\mathrm{PaO}_{2}(\mathrm{mmHg})$ & $81[62-100]$ & 80 [57-93] & 96 [72-102] & 0.18 \\
\hline With delivered $\mathrm{O}_{2}$ flow (L/min) & $3[2-4.5]$ & $3[2-4.8]$ & $3[2-4]$ & \\
\hline $\mathrm{PaO}_{2} / \mathrm{FiO}_{2}$ ratio $(\mathrm{mmHg})$ & 259 [217-302] & 254 [214-277] & 300 [229-317] & 0.19 \\
\hline $\mathrm{PaCO}_{2}(\mathrm{mmHg})$ & $44[40-48]$ & $43[41-48]$ & $47[39-49]$ & 0.54 \\
\hline $\mathrm{SaO}_{2}(\%)$ & $95[93-97.2]$ & 95 [90-97] & 97 [93.9-97.6] & 0.27 \\
\hline
\end{tabular}

SOFA score Sequential Organ Failure Assessment score, SAPS // Simplified Acute Physiologic Score II

a Biological data available for the 56 patients, except for haemoglobin S available for $41 / 56$ patients ( 29 with a favourable outcome and 12 with a complicated outcome)

b Blood gas results available for 53 patients ( 39 with a favourable outcome and 14 with a complicated outcome) 
Table 3 Data course and outcomes

\begin{tabular}{|c|c|c|c|c|}
\hline \multirow[t]{2}{*}{ Data course and outcomes } & \multirow{2}{*}{$\begin{array}{l}\text { All patients } \\
(n=56)\end{array}$} & \multicolumn{2}{|l|}{ Patients with } & \multirow[t]{2}{*}{$p$} \\
\hline & & $\begin{array}{l}\text { Favourable outcome } \\
(n=42)\end{array}$ & $\begin{array}{l}\text { Complicated outcome } \\
(n=14)\end{array}$ & \\
\hline \multicolumn{5}{|l|}{ Oxygen delivery (L/min), median [IQR] } \\
\hline Mean $\mathrm{O}_{2}$ flow at D0 & $3.2[2.3$ to 4.5$]$ & $3.2[2.3$ to 4.3$]$ & $3.6[2.6$ to 4.9$]$ & 0.54 \\
\hline Mean $\mathrm{O}_{2}$ flow change at $\mathrm{D} 2^{\mathrm{a}}$ & $-0.9[-2.4$ to -0.1$]$ & $-1[-2.4$ to -0.2$]$ & $-0.6[-1.3$ to 0$]$ & 0.53 \\
\hline \multicolumn{5}{|l|}{ Numeric Pain Scale values, median [IQR] } \\
\hline Mean NPS at D0 & $4[2.4$ to 6$]$ & $3.9[2$ to 6$]$ & $4.2[3.9$ to 6.3$]$ & 0.23 \\
\hline Mean NPS change at D2 ${ }^{\mathrm{a}}$ & $-1.7[-3.5$ to -0.6$]$ & $-1.7[-3.6$ to -0.8$]$ & $-1.3[-3.4$ to 0.1$]$ & 0.33 \\
\hline \multicolumn{5}{|l|}{ Respiratory rate (/min), median [IQR] } \\
\hline Respiratory rate at D0 & 24 [20 to 29] & 23 [20 to 29] & 27 [23 to 31$]$ & 0.16 \\
\hline Respiratory rate change at $\mathrm{D} 2^{\mathrm{a}}$ & $-5[-7$ to -1.5$]$ & $-5[-7$ to -0.5$]$ & $-4[-6$ to -2.8$]$ & 0.70 \\
\hline \multicolumn{5}{|l|}{ Laboratory values, median [IQR] } \\
\hline Haemoglobin at D0 (g/dL) & 7.5 [6.9 to 8.5$]$ & $7.5[6.9$ to 8.7$]$ & $7.4[6.5$ to 7.8$]$ & 0.18 \\
\hline Haemoglobin change at D2 $(\mathrm{g} / \mathrm{dL})^{\mathrm{a}}$ & $+0.2[-0.6$ to 1.5$]$ & $+0.1[-0.6$ to 0.6$]$ & $+0.9[-0.1$ to 1.5$]$ & 0.03 \\
\hline Platelets at D0 (G/L) & 327 [298 to 403] & $329[264$ to 403$]$ & $325[294$ to 434$]$ & 0.76 \\
\hline Platelets change at D2 $(\mathrm{G} / \mathrm{L})^{\mathrm{a}}$ & $+18[-18$ to 23$]$ & $+26[0$ to 74$]$ & $-2[-34$ to 38$]$ & 0.08 \\
\hline LDH at D0 (UI/L) & $544[420$ to 745$]$ & $503[403$ to 715$]$ & $613[525$ to 834$]$ & 0.09 \\
\hline LDH change at D2 (UI/L) & $-47[-153$ to -7$]$ & $-58[-145$ to -18$]$ & $-24[-205$ to 90$]$ & 0.44 \\
\hline Bilirubin at D0 $(\mu \mathrm{mol} / \mathrm{L})$ & $47[33$ to 79$]$ & $55[38$ to 79$]$ & $36[29$ to 44$]$ & 0.06 \\
\hline Bilirubin change at D2 $(\mu \mathrm{mol} / \mathrm{L})^{\mathrm{a}}$ & $-12[-29$ to -6$]$ & $-15[-35$ to -6$]$ & $-9[-12$ to -3$]$ & 0.10 \\
\hline \multicolumn{5}{|l|}{ SOFA score (points), median [IQR] } \\
\hline SOFA score at D0 & $4[3$ to 4$]$ & $3[3$ to 4$]$ & $4[3$ to 4$]$ & 0.30 \\
\hline SOFA score change at D2 ${ }^{\mathrm{a}}$ & $-1[-1$ to 0$]$ & $-1[-1$ to -1$]$ & $-0.5[-1$ to 0$]$ & 0.09 \\
\hline \multicolumn{5}{|l|}{ Lung ultrasound data, median [IQR] } \\
\hline LU score at D0 & 24 [20 to 28$]$ & 25 [20 to 28$]$ & 22.5 [18 to 26$]$ & 0.17 \\
\hline LU score change at $\mathrm{D}^{\mathrm{a}}$ & $-5[-11$ to 1$]$ & $-7[-12$ to -5$]$ & $+2[-2.5$ to 5$]$ & $<0.001$ \\
\hline LU re-aeration score between D2 and D0 $0^{\mathrm{a}}$ & $5[-3$ to 10.5$]$ & $7.5[4.5$ to 15$]$ & $-3[-6.5$ to 1.8$]$ & $<0.001$ \\
\hline \multicolumn{5}{|l|}{ Inspiratory vital capacity (mL), median [IQR] } \\
\hline Inspiratory vital capacity at D0 & 1000 [600 to 1250$]$ & 1000 [600 to 1300$]$ & 750 [500 to 1100$]$ & 0.12 \\
\hline Inspiratory vital capacity change at D2 ${ }^{\mathrm{a}}$ & $+250[25$ to 500$]$ & $+500[150$ to 600$]$ & $+250[0$ to 250$]$ & 0.01 \\
\hline Empirical antimicrobial therapy, \% (n) & $98 \%(55)$ & $98 \%(41)$ & $100 \%(14)$ & 0.56 \\
\hline Microbiologically documented pneumonia, \% (n) & $20 \%(11)$ & $21 \%(9)$ & $14 \%(2)$ & 0.71 \\
\hline \multicolumn{5}{|l|}{ Transfusion, \% (n) or median [IQR] } \\
\hline Transfusion & $57 \%(32)$ & $45 \%(19)$ & $93 \%(13)$ & 0.005 \\
\hline Total number of RBC units & 1 [0 to 2$]$ & 0 [0 to 2] & $2[2$ to 3$]$ & $<0.001$ \\
\hline \multicolumn{5}{|l|}{ Mechanical ventilation, \% ( $n$ ) } \\
\hline Non-invasive & $2 \%(1)$ & $0 \%(0)$ & $7 \%(1)$ & 0.02 \\
\hline Invasive & $2 \%(1)$ & $0 \%(0)$ & $7 \%(1)$ & \\
\hline \multicolumn{5}{|l|}{ Length-of-stay (days), median [IQR] } \\
\hline ICU & $5[4$ to 6$]$ & $4[4$ to 5$]$ & $7[7$ to 8$]$ & - \\
\hline Hospital & 8 [6 to 11.3$]$ & 7 [5 to 9] & 13 [10.3 to 14$]$ & $<0.001$ \\
\hline Death, \% (n) & $0 \%(0)$ & $0 \%(0)$ & $0 \%(0)$ & - \\
\hline
\end{tabular}

${ }^{a}$ Values for changes between D0 and D2 are reported for the 48 patients that were not discharged from the ICU before D2 (14 patients with a complicated and 34 with a favourable outcome)

At D2, LU patterns showed a moderate regression of aeration loss, with lung consolidation still reaching $79 \%$ and $69 \%$ of patients for left and right postero-inferior regions, respectively (Fig. 2). The LUS decreased from 24 [20-28] to 20 [15-24] between D0 and D2 $(p<0.001)$, with more improvement in patients with a favourable 
(See figure on next page.)

Fig. 2 Distribution of the Lung Ultrasound (LU) patterns among the 12 lung regions for the whole cohort (a), and patients with a favourable (b) or a complicated (c) outcome, at inclusion (left bar in each lung region) and D2 (right bar in each lung region). Lungs were divided in 12 regions: left and right antero-superior regions were numbered 1 and 7, respectively; antero-inferior regions 2 and 8; latero-superior regions 3 and 9; latero-inferior regions 4 and 10; postero-superior regions 5 and 11; and postero-inferior regions 6 and 12. The main LU pattern was large bilateral lung consolidations, predominantly distributed in dependent pulmonary areas (regions 4-6 for left lung and 10-12 for right lung). "N": normal aeration; "B1": moderate loss of aeration; "B2": severe loss of aeration; "C": lung consolidation

outcome (Additional file 3: Figure S3A). The overall LU re-aeration score between D0 and D2 was 5 [-3 to 9.5]. Patients with a complicated outcome had a significantly lower re-aeration score than their counterparts $(-3$ [ -6.5 to 1.8$]$ vs. 7.5 [4.5-15], $p<0.001$ ) (Additional file 3: Figure S3B and Table 3).

\section{Lung inspiratory vital capacity}

IVC was dramatically impaired at D0 (1000 [600-1250] $\mathrm{mL}$, corresponding to $24[16-35] \%$ of the predicted forced vital capacity). Overall IVC significantly increased between D0 and D2 (1250 [1000-1690] mL, $p=0.05$ vs. D0). Patients with a complicated outcome had a significantly lower IVC increase at D2 than their counterparts $(+250[0-250]$ vs. $+500[150-600] \mathrm{mL}, p=0.003$; Table 3). IVC change between D0 and D2 was correlated with the LU re-aeration score $(r=0.66-p<0.0001-$ Additional file 3: Figure S4).

\section{Outcomes}

\section{ICU and hospital length-of-stays}

Overall, ICU and hospital length-of-stays were 5 [4-5.3] and 8 [6-11.3] days after inclusion, respectively. Compared to patients with a favourable outcome, lengthof-stay of patients with a complicated outcome, by definition longer in ICU, was also significantly prolonged for the total hospital stay (Table 3). Patients with a positive LU re-aeration score had shorter ICU and hospital length-of-stays than patients with a negative re-aeration score (Fig. 3a, b). Patients with an increase of IVC at D2 had shorter ICU length-of-stay than patients without IVC increase, whereas there was no difference in hospital length-of-stay (Fig. 3c, d).

\section{Transfusion}

Thirty-two patients (57\%) were transfused with 2 [2] RBC units, among whom 13 had a combined phlebotomy. Among the 7 patients with complicated outcome who were transfused with $\geq 3 \mathrm{RBC}$ units, the third $\mathrm{RBC}$ unit was transfused 2 [2-3] days after inclusion. Patients with a positive LU re-aeration score had significantly fewer transfusion episodes (Additional file 3: Figure $\mathrm{S} 5 \mathrm{~A})$, and received fewer RBC units (1 [0-2] vs. 2 [1-3] units, $p=0.003$ ) than patients with a negative LU re-aeration score. Conversely, there was no difference between patients with and without IVC increase in the number of transfusion episodes and RBC units transfused (1 [0-2] vs. $2[0-3]$ units, $p=0.37$ ) (Additional file 3: Figure S5B).

\section{Mechanical ventilation and death}

Finally, 2 patients were mechanically ventilated (1 noninvasively at day 5 post-inclusion and 1 invasively at day 9 post-inclusion), both with a negative LU re-aeration score but an increased IVC at D2. No deaths were observed.

\section{Parameters associated with outcome}

In univariate analysis, the only parameters significantly associated with the composite outcome criterion were LU re-aeration score and IVC change at D2 (Additional file 6: Table S1). After adjustment for age, baseline $\mathrm{Hb}$ and $\mathrm{LDH}$ value at inclusion, $\mathrm{LU}$ re-aeration score and IVC change at D2 remained independently associated with outcome (OR 0.62 [0.43-0.89] per point and 0.66 [0.46-0.95] per $100 \mathrm{~mL}$, respectively) (Additional file 6: Table S1). The best area under the ROC curve associated with complicated outcome was obtained for the LU reaeration score $(0.87$ [0.79-0.98] vs. 0.76 [0.62-0.90] for IVC change, $p=0.041$ ) (Fig. 4). A negative LU re-aeration score between D0 and D2 (i.e., cut-off value of 0 ) had $71.4 \%$ sensitivity, $91.2 \%$ specificity and a positive likelihood ratio of 8 to predict complicated outcome.

\section{Discussion}

Our main results may be summarized as follows: (1) severe ACS patients had a considerable morphological and functional loss of lung aeration and (2) early variation of lung aeration loss estimated by a bedside morpho-functional approach is independently associated with complicated outcome.

In our study, the main ACS morphological pattern was large bilateral lung consolidations, predominantly distributed in dependent pulmonary areas. Our results are concordant with previous CT-scan reports $[9,14,21]$ and with the only other study that used LU in ACS patients admitted to the ICU [22]. Lungs of ACS patients showed a dramatic loss of aeration leading to severe impairment of vital capacity and high initial LUS. Distribution of ACS lung consolidation does not evocate classical bacterial pneumonia, in which no zonal predilection is usually reported $[16,23]$. Thus, non-infectious mechanisms 

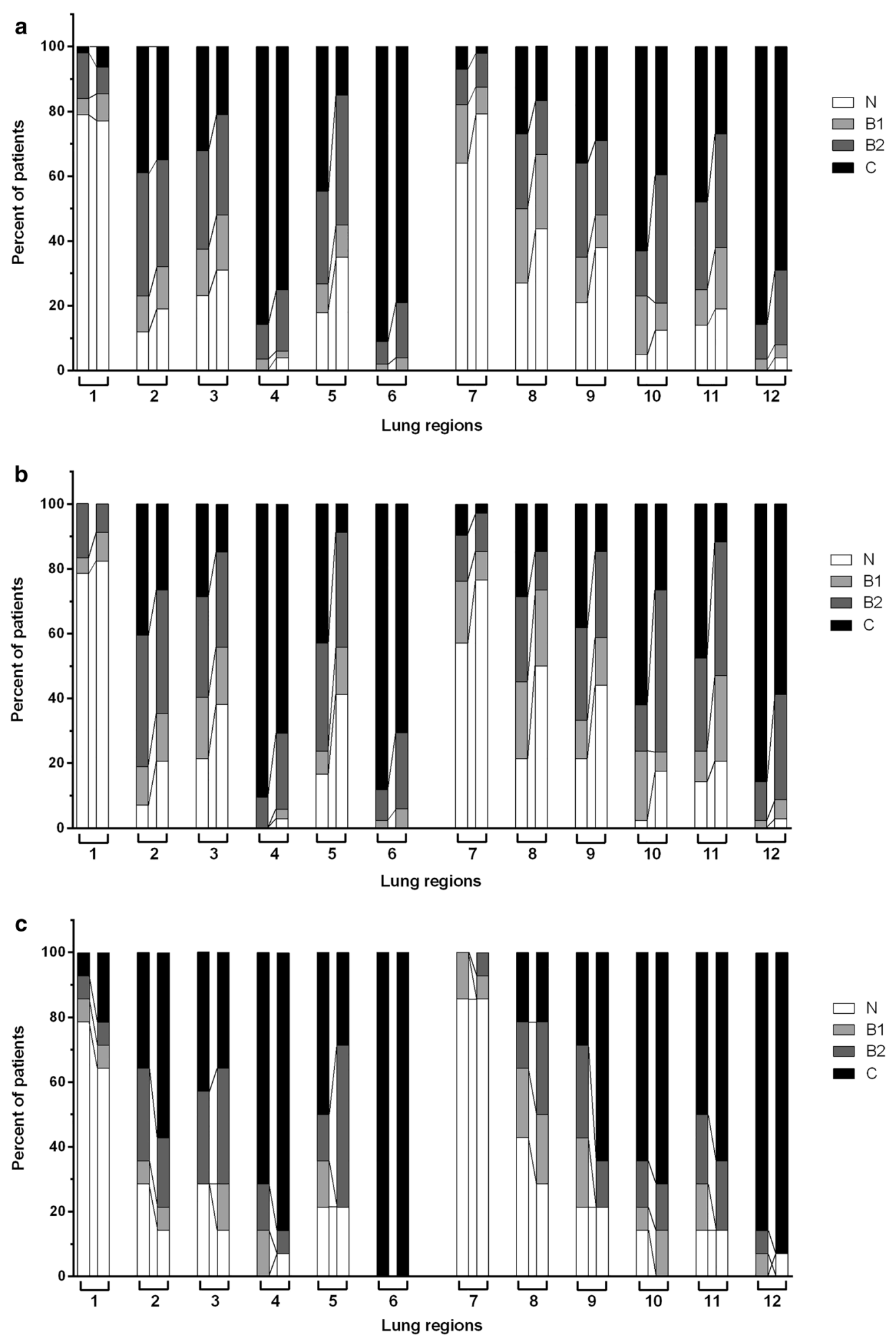

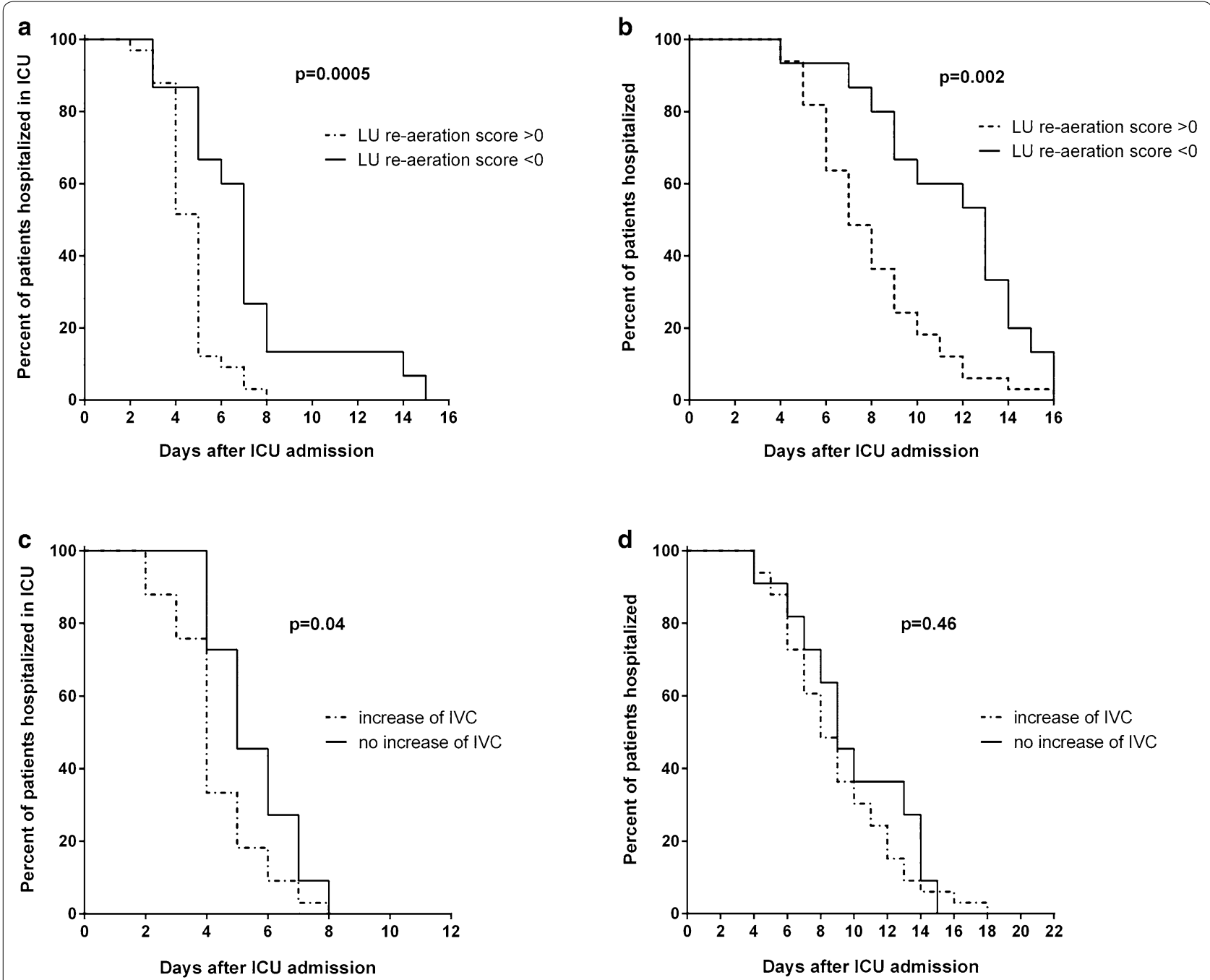

Fig. 3 Length-of-stay in the intensive care unit (ICU) and in the hospital according to the lung aeration assessed by the lung ultrasound (LU) re-aeration score or the inspiratory vital capacity (IVC). Patients with a negative LU re-aeration score had longer stays in ICU (a) and in hospital (b) than patients with a positive LU re-aeration score. Patients with an increased IVC at D2 had a slightly shorter ICU stay than patients without IVC increase $(\mathbf{c})$, while there were no differences between groups in hospital length-of-stay (d)

may also act in ACS, such as inflammatory oedema, diaphragmatic course limitation, and lower lobe collapse, notably due to the pressure exerted by a dilated right heart [9]. However, ACS patient tolerance of this severe acute lung injury is startlingly good, requiring mechanical ventilation in less than $5 \%$ of cases in our cohort, as in other recent reports $[9,24]$. The discrepancy between the severity of morphologic and functional lung damages and the moderate hypoxemia observed in these patients may contribute to the low incidence of mechanical ventilation. Such a discrepancy, in our study as in others $[9,22]$, may be, at least in part, explained by enhanced microvascular response to hypoxia [25, 26] leading to increased acute hypoxic pulmonary vasoconstriction. In addition, the functional shunt in the collapsed lung may be further reduced by sickle red blood cells entrapment in these most hypoxic regions, leading to a large redistribution of blood flow toward the upper lobes. This might contribute to explain the existence of an association between the morpho-functional evaluation of lung aeration loss and the outcome, and the absence of such an association for oxygenation parameters.

Early detection of ACS patients who will experience a complicated outcome is a major concern, since it would allow physicians to modify their management accordingly. To date, a simple and easily accepted diagnostic tool of ACS severity is lacking for severe patients admitted to the ICU. None of the specific tools associated with 


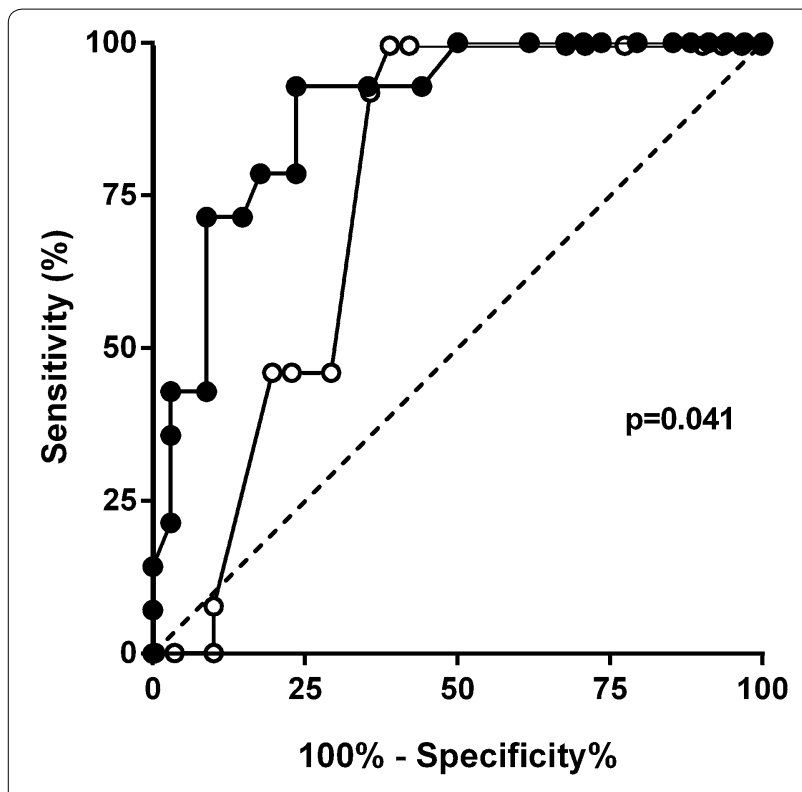

$\mathrm{AUC}_{\text {re-aeration score }}=0.8995 \% \mathrm{Cl}(0.79-0.98) ; \mathrm{p}<0.001$

$\mathrm{AUC}_{\triangle \mathrm{IVC} \text { MAх }}=0.7695 \% \mathrm{Cl}(0.62-0.90) ; \mathrm{p}=0.007$

Fig. 4 Receiver operating characteristic (ROC) curves for the lung ultrasound (LU) re-aeration score (black symbols) and the inspiratory vital capacity (IVC) change (white symbols) for the diagnosis of acute chest syndrome (ACS) severity. If both the LU re-aeration score and IVC change had good accuracy for diagnosing ACS severity, the area under the ROC curve (AUC) for the LU re-aeration score was significantly better than that of IVC

worsening evolution in ACS patients hospitalized in the wards (such as LDH concentration) [27] or in SCD patients referred to the ICU for mixed causes (such as changes in haemoglobin level or respiratory rate) [3], were associated with complicated outcome in our study. In addition, platelets count that has been reported to be predictive of rapidly progressive ACS [28], and its change between D0 and D2, were similar between patients with favourable and complicated outcomes. Eventually, general ICU prognostic tools such as SAPSII or SOFA scores at inclusion were not associated with complicated outcome, nor did SOFA change between D0 and D2. On the other hand, the early change of lung aeration loss appeared as a good severity parameter, morphologically estimated by LU and functionally estimated by bedside spirometry. If both evaluate lung aeration, they did not strictly evolve in a parallel manner, suggesting that a dual morphological and functional evaluation might be interesting. Indeed, several confounders other than lung aeration can influence vital capacity measurement, such as chest pain, patient tiredness, or even the method used to perform spirometry as reported in out-patients $[29,30]$.
Another limit of bedside spirometry to predict outcome is that the difference between the increase in vital capacity among patients with a favourable and a complicated outcome is weak, often inferior to the intra-individual variations that were observed within the repeated measures performed on each patient during the study. Thus, using only bedside spirometry as a predictive tool may be a source of error.

LU examination appears as an interesting complementary tool. In our study, LU showed the best area under the ROC curve associated with complicated outcome. LU allows for visual assessment of lung aeration, also providing the regional patterns of lung injury. LU is also useful in diagnosing pleural effusion $[8,31]$, and providing information on diaphragm function [32-34]. Some possible inconsistency of the lung ultrasound score (LUS) and a perfectible points allocation scale have been pointed out [35]. Indeed, " 0 point" in an individual lung region does not necessarily reflect normal lung aeration and "3 points" complete loss of lung aeration. However, the LUS is a simple tool to provide a numerical quotation of the lung aeration that offers the advantages of being quickly calculated and easily understood by all LU practitioners. In addition, its validity is reinforced by the highly reproducible rating of lung aeration between examiners, in our study as in others [8], meaning that a LUS improvement most likely corresponds to a regression of the lung aeration loss. Finally, LU allows for bedside assessment of lung aeration without exposing patients to X-ray. This is an obvious advantage given the recurrence of ACS episodes during the lifespan of SCD patients, who receive an important dose of radiations among their life with current diagnostic strategies, among which an important part could be avoided implementing LU.

LU presents some limitations, among which availability of the technique and experience of physicians are probably the two most recurrent ones. The usefulness of LU in critically ill patients is now clearly demonstrated [31], leading to considerable improvement in availability of the technique. The development of an easy-to-use singleprobe portable device mainly dedicated to LU could be a solution to democratize its use definitively. In addition, if training of ICU physicians has recently significantly increased, practicing in good quality training centres remains essential to improve learning and reinforce $\mathrm{LU}$ diagnostic performances. In these conditions, the learning curve of LU is short [36,37], which could allow any physician involved in the management of SCD patients in the ICU, in the emergency room and even in the wards to quickly acquire the skills required to follow the ACSinduced lung aeration loss [38]. Then, it could be hypothesized that LU may be made in first line, and if possible replace chest X-ray for ACS diagnosis and follow-up in 
the near future, notably as chest X-ray performed in ICU lacks sensitivity and specificity in particular in ACS patients [9].

Our study presents some limitations. Conversely to previous results reported by Razazi et al. [22], initial LU seems not sufficient to determine severity and only dynamic parameters were informative in our study. This difference may be explained by the use of different scoring systems to transform LU images into numerical results between the two studies. This result may also be due to a lack of power related to the number of patients assessed with LU at D0 in our study. Eventually, this result may be explained by a difference in severity between the populations included in the two studies, in particular as the transfusion rate was $82 \%$ in the study of Razazi et al. [22] and 57\% in the present one. However, all the other clinical and biological parameters reflecting the severity of an ACS are similar between the two cohorts. This rather suggests that our transfusion policy, based on a systematic joint assessment of the indication of the transfusion between the intensivist and the SCD referring physician and on the evaluation of the clinical course over the first $6 \mathrm{~h}$ in the ICU before transfusing, may be more restrictive than that of other centres. Thus, it could be hypothesized that the discrepancy between LU results at D0 and patient's severity may be explained by the contribution of a chronic loss of aeration existing at steady state. Indeed, it was recently reported that 3 among 14 (21\%) patients with SCD presenting to the emergency department for pain crisis and who did not developed ACS had however echographic lung consolidations [39]. These results suggest that lung aeration loss could exist chronically in SCD patients at steady state and/or occur in the event of an acute non-thoracic SCD-related event. Thus, a consolidation threshold associated with severity may be an interesting diagnostic tool but needs to be specified in larger studies. In this context, the early evolution of LUS, comparing data to those obtained in the same patient shortly before, seems a more reliable strategy to diagnose ACS severity. This questions the clinical relevance of such a two-point strategy and its real impact on patient care. In our study the evolution of lung aeration during the first 2 days was strongly associated with outcome events occurring beyond this time point. This requires further determination of the optimal timing for lung aeration re-assessment.

\section{Conclusion}

Patients with severe ACS have a dramatic loss of lung aeration. Serial bedside spirometry and LU examination accurately assess the ACS-related lung aeration loss and allow for early identification of patients who will experience a complicated outcome. A negative LU re-aeration score is the best independent parameter associated with a complicated course among all clinical and complementary examination parameters. Together, our results suggest that early evolution of lung aeration loss could be a reliable criterion to define ACS severity.

\section{Supplementary information}

Supplementary information accompanies this paper at https://doi. org/10.1186/s13613-019-0583-y.

Additional file 1. The additional method file provides additional details on methods used in the study.

Additional file 2 . The additional file provides the STROBE checklist related to the content of the manuscript.

Additional file 3. The additional figures file provides 5 additional figures.

Additional file 4. The additional video file provides LU video loops of the 4 characteristic LU patterns.

Additional file $\mathbf{5}$. The additional results file provides additional results on lung ultrasound examination.

Additional file 6 . The additional table file provides the results of the multivariate analysis of parameters associated with complicated outcome.

\section{Abbreviations}

ACS: acute chest syndrome; CT-scan: computed tomography scan; ICU: intensive care unit; IVC: inspiratory vital capacity; LU: lung ultrasound; LUS: lung ultrasound score; LUS-D0: lung ultrasound score at inclusion (D0); LUSD2: lung ultrasound score $48 \mathrm{~h}$ after inclusion (D2); RBC: red blood cell; SCD: sickle-cell disease.

\section{Acknowledgements}

The authors thank Joanna Shore for English proofreading.

\section{Authors' contributions}

MG conceived the protocol, randomly read the LU video loops, analysed the collected data, and drafted the manuscript. EMH participated in the protocol conception, performed LU examinations and corrected the manuscript. CA randomly read the LU video loops, and corrected the manuscript. CQ and MF participated in the protocol conception, helped MG to analyse the collected data, and corrected the manuscript. CB, KSS, FL, FB, and JPF contributed to patient care and corrected the manuscript. All authors read and approved the final manuscript.

Funding

This study was not funded by any external source.

\section{Availability of data and materials}

The data sets used and analysed during the current study are available from the corresponding author on reasonable request.

\section{Ethics approval and consent to participate}

According to French law, this study was approved by the Institutional Review Board (CPP"Ile-de-France VI", Paris, France, \#07-02-2013), and the French national commission on digital storage of personal data (CNIL, no. 1643704) [40]. Information was given directly to patients who accepted data and LU video collection.

Consent for publication

Not applicable.

\section{Competing interests}

The authors declare that they have no competing interests. 


\begin{abstract}
Author details
1 Département d'Anesthésie et Réanimation, APHP Hôpital Tenon, 4 rue de la Chine, 75020 Paris, France. ${ }^{2}$ Service de Réanimation Médico-Chirurgicale, APHP Hôpital Tenon, Paris, France. ${ }^{3}$ Université Pierre et Marie Curie Sorbonne Université, Paris, France. ${ }^{4}$ Département d'Anesthésie et Réanimation, APHP Hôpital de la Pitié-Salpêtrière, Paris, France. ${ }^{5}$ Service de Médecine Interne et Centre de Référence de la Drépanocytose, APHP Hôpital Tenon, Paris, France.
\end{abstract}

Received: 18 April 2019 Accepted: 21 September 2019 Published online: 30 September 2019

\section{References}

1. Direction de la recherche, des études, de l'évaluation et des statistiques. Etat de la santé de la population en France-Rapport 2017. 2017. http:// drees.solidarites-sante.gouv.fr/IMG/pdf/esp2017.pdf. Accessed 10 Jul 2018

2. Lucas S, Mason D, Mason M, Weyman D. Report of the National Confidential Enquiry into Patient Outcome and Death. National Confidential Enquiry into Patient Outcome and Death (NCEPOD); 2008. http://www. ncepod.org.uk/2008report1/Downloads/Sickle_report.pdf\#search='sickl e.

3. Cecchini J, Lionnet F, Djibré M, Parrot A, Stojanovic KS, Girot R, et al. Outcomes of adult patients with sickle cell disease admitted to the ICU: a case series. Crit Care Med. 2014;42:1629-39.

4. Perronne V, Roberts-Harewood M, Bachir D, Roudot-Thoraval F, Delord J-M, Thuret I, et al. Patterns of mortality in sickle cell disease in adults in France and England. Hematol J Off J Eur Haematol Assoc EHA. 2002;3:56-60

5. Vichinsky EP, Neumayr LD, Earles AN, Williams R, Lennette ET, Dean D, et al. Causes and outcomes of the acute chest syndrome in sickle cell disease. National Acute Chest Syndrome Study Group. N Engl J Med. 2000;342:1855-65.

6. Gladwin MT, Vichinsky E. Pulmonary complications of sickle cell disease. N Engl J Med. 2008;359:2254-65.

7. Vichinsky EP, Styles LA, Colangelo LH, Wright EC, Castro O, Nickerson B. Acute chest syndrome in sickle cell disease: clinical presentation and course. Cooperative Study of Sickle Cell Disease. Blood. 1997;89:1787-92.

8. Lichtenstein D, Goldstein I, Mourgeon E, Cluzel P, Grenier P, Rouby J-J. Comparative diagnostic performances of auscultation, chest radiography, and lung ultrasonography in acute respiratory distress syndrome. Anesthesiology. 2004;100:9-15.

9. Mekontso Dessap A, Deux J-F, Habibi A, Abidi N, Godeau B, Adnot S, et al. Lung imaging during acute chest syndrome in sickle cell disease: computed tomography patterns and diagnostic accuracy of bedside chest radiograph. Thorax. 2014;69:144-51.

10. Lichtenstein DA, Lascols N, Mezière G, Gepner A. Ultrasound diagnosis of alveolar consolidation in the critically ill. Intensive Care Med. 2004;30:276-81.

11. Habibi A, Arlet J-B, Stankovic K, Gellen-Dautremer J, Ribeil J-A, Bartolucci $P$, et al. Centre de référence maladies rares «syndromes drépanocytaires majeurs». [French guidelines for the management of adult sickle cell disease: 2015 update]. Rev Med Internet. 2015;36:3-84

12. Bellet PS, Kalinyak KA, Shukla R, Gelfand MJ, Rucknagel DL. Incentive spirometry to prevent acute pulmonary complications in sickle cell diseases. N Engl J Med. 1995:333:699-703.

13. Von Elm E, Altman DG, Egger M, Pocock SJ, Gøtzsche PC, Vandenbroucke JP, STROBE Initiative. The Strengthening the Reporting of Observational Studies in Epidemiology (STROBE) statement: guidelines for reporting observational studies. J Clin Epidemiol. 2008;61:344-9.

14. De Prost N, Sasanelli M, Deux J-F, Habibi A, Razazi K, Galactéros F, et al. Positron emission tomography with 18F-fluorodeoxyglucose in patients with sickle cell acute chest syndrome. Medicine (Baltimore). 2015;94:e821.

15. Tawfic QA, Kausalya R, AI-Sajee D, Burad J, Mohammed AK, Narayanan A. Adult sickle cell disease: a five-year experience of intensive care management in a university hospital in Oman. Sultan Qaboos Univ Med J. 2012:12:177-83.

16. Bouhemad B, Liu Z-H, Arbelot C, Zhang M, Ferarri F, Le-Guen M, et al. Ultrasound assessment of antibiotic-induced pulmonary reaeration in ventilator-associated pneumonia. Crit Care Med. 2010;38:84-92.
17. Bouhemad B, Brisson H, Le-Guen M, Arbelot C, Lu Q, Rouby J-J. Bedside ultrasound assessment of positive end-expiratory pressure-induced lung recruitment. Am J Respir Crit Care Med. 2011;183:341-7.

18. American Thoracic Society/European Respiratory Society. ATS/ERS Statement on respiratory muscle testing. Am J Respir Crit Care Med. 2002;166:518-624.

19. Hebbel RP, Boogaerts MA, Eaton JW, Steinberg MH. Erythrocyte adherence to endothelium in sickle-cell anemia. A possible determinant of disease severity. N Engl J Med. 1980:302:992-5.

20. Lee K, Gane P, Roudot-Thoraval F, Godeau B, Bachir D, Bernaudin F, et al. The nonexpression of CD36 on reticulocytes and mature red blood cells does not modify the clinical course of patients with sickle cell anemia. Blood. 2001;98:966-71.

21. Bhalla M, Abboud MR, McLoud TC, Shepard JA, Munden MM, Jackson SM, et al. Acute chest syndrome in sickle cell disease: CT evidence of microvascular occlusion. Radiology. 1993;187:45-9.

22. Razazi K, Deux J-F, de Prost N, Boissier F, Cuquemelle E, Galactéros F, et al. Bedside lung ultrasound during acute chest syndrome in sickle cell disease. Medicine (Baltimore). 2016;95:e2553.

23. Nambu A, Ozawa K, Kobayashi N, Tago M. Imaging of communityacquired pneumonia: roles of imaging examinations, imaging diagnosis of specific pathogens and discrimination from noninfectious diseases. World J Radiol. 2014;6:779-93.

24. Allareddy V, Roy A, Lee MK, Nalliah RP, Rampa S, Allareddy V, et al. Outcomes of acute chest syndrome in adult patients with sickle cell disease: predictors of mortality. PLOS ONE. 2014;9:e94387.

25. Haynes J, Taylor AE, Dixon D, Voelkel N. Microvascular hemodynamics in the sickle red blood cell perfused isolated rat lung. Am J Physiol. 1993:264:H484-9.

26. Sangkatumvong S, Khoo MCK, Kato R, Detterich JA, Bush A, Keens $\mathrm{TG}$, et al. Peripheral vasoconstriction and abnormal parasympathetic response to sighs and transient hypoxia in sickle cell disease. Am J Respir Crit Care Med. 2011:184:474-81.

27. Stankovic Stojanovic K, Steichen O, Lefevre G, Bachmeyer C, Avellino V, Grateau G, et al. High lactate dehydrogenase levels at admission for pain ful vaso-occlusive crisis is associated with severe outcome in adult SCD patients. Clin Biochem. 2012;45:1578-82.

28. Chaturvedi S, Ghafuri DL, Glassberg J, Kassim AA, Rodeghier M, DeBaun MR. Rapidly progressive acute chest syndrome in individuals with sickle cell anemia: a distinct acute chest syndrome phenotype. Am J Hematol. 2016;91:1185-90.

29. Giner J, Plaza V, Rigau J, Solà J, Bolíbar I, Sanchis J. Spirometric standards and patient characteristics: an exploratory study of factors affecting fulfillment in routine clinical practice. Respir Care. 2014;59:1832-7.

30. Sipoli L, Martinez L, Donária L, Probst VS, Moreira GL, Pitta F. Spirometry in healthy subjects: do technical details of the test procedure affect the results? PLOS ONE. 2014;9:e107782.

31. Volpicelli G, Elbarbary M, Blaivas M, Lichtenstein DA, Mathis G, Kirkpatrick AW, et al. International evidence-based recommendations for point-ofcare lung ultrasound. Intensive Care Med. 2012;38:577-91.

32. He L, Zhang W, Zhang J, Cao L, Gong L, Ma J, et al. Diaphragmatic motion studied by M-mode ultrasonography in combined pulmonary fibrosis and emphysema. Lung. 2014;192:553-61.

33. Ferrari G, De Filippi G, Elia F, Panero F, Volpicelli G, Aprà F. Diaphragm ultrasound as a new index of discontinuation from mechanical ventilation. Crit Ultrasound J. 2014;6:8

34. Goligher EC, Laghi F, Detsky ME, Farias P, Murray A, Brace D, et al. Measuring diaphragm thickness with ultrasound in mechanically ventilated patients: feasibility, reproducibility and validity. Intensive Care Med. 2015:41:642-9.

35. Lichtenstein DA. Current misconceptions in lung ultrasound: a short guide for experts. Chest. 2019;156:21-5.

36. Charbonneau H, Arbelot C, Bouhemad B, Rouby J. Assessment of the learning curve of anesthesiology and intensive care residents for general ultrasound examination. Ann Fr Anesth Reanim. 2009;28(S185):2009.

37. Chalumeau-Lemoine L, Baudel J-L, Das V, Arrivé L, Noblinski B, Guidet $B$, et al. Results of short-term training of naïve physicians in focused general ultrasonography in an intensive-care unit. Intensive Care Med. 2009;35:1767-71.

38. Lichtenstein DA. Lung ultrasound in the critically ill. Ann Intensive Care 2014:4:1. 
39. Colla JS, Kotini-Shah P, Soppet S, Chen Y-F, Molokie R, Prajapati P, et al. Bedside ultrasound as a predictive tool for acute chest syndrome in sickle cell patients. Am J Emerg Med. 2018;36:1855-61.

40. Toulouse E, Masseguin C, Lafont B, McGurk G, Harbonn A, Roberts J, et al. French legal approach to clinical research. Anaesth Crit Care Pain Med. 2018;37:607-14.

\section{Publisher's Note}

Springer Nature remains neutral with regard to jurisdictional claims in published maps and institutional affiliations.
Submit your manuscript to a SpringerOpen ${ }^{\odot}$ journal and benefit from:

- Convenient online submission

- Rigorous peer review

- Open access: articles freely available online

- High visibility within the field

- Retaining the copyright to your article

Submit your next manuscript at $\boldsymbol{\nabla}$ springeropen.com 